\title{
NARRATIVAS ENTRE CIÊNCIA E POLÍTICA NO ATIVISMO DA CLOROQUINA

\author{
NARRATIVAS ENTRE CIENCIA Y POLÍTICA
} \\ EN EL ACTIVISMO DE CLOROQUINA \\ NARRATIVES BETWEEN SCIENCE AND POLITICS IN CHLOROQUINE ACTIVISM
}

\author{
André Luiz Machado das Neves ${ }^{1}$ e Breno de Oliveira Ferreira ${ }^{2}$ \\ ${ }^{1}$ Universidade do Estado do Amazonas, Manaus/AM, Brasil \\ ${ }^{2}$ Universidade Federal do Amazonas, Manaus/AM, Brasil
}

RESUMO: A atual crise sanitária e pandêmica gerou um conjunto de tensões, tramas e embates de amplitude global e entre diferentes espaços científicos, político-partidário e econômicos. Os medicamentos hidroxicloroquina e cloroquina ganharam fama e expectativas. O que até então servia para o tratamento apenas da malária, agora tinha "possibilidade de cura" para a Covid-19. Neste artigo, buscamos compreender o debate entre ciência e política gerado através de uma pesquisa com cloroquina (CloroCovid-19), desenvolvida em Manaus, Amazonas. Por meio de uma etnografia tecida em documentos como vídeos, notas, cartas e mensagens veiculadas nas mídias sociais, fizemos a descrição e análise: (a) do que chamamos de ativismo da cloroquina em Manaus e sua ofensiva; (b) da consequente reação acadêmica frente aos ataques. Ambos os polos - pró e contra - fizeram esforços na construção de uma verdade, em que a ciência e a política se reticulam constantemente.

PALAVRAS-CHAVE: Covid-19; Ciência; Política; Cibercultura.

RESUMEN: La actual crisis sanitaria y pandémica ha generado un conjunto de tensiones, tramas y enfrentamientos de alcance global y entre diferentes espacios científicos, políticos y económicos. Las drogas hidroxicloroquina y cloroquina han ganado fama y expectativas. Lo que hasta entonces solo servía para tratar la malaria, ahora tenía una "posibilidad de cura" para Covid-19. En este artículo, buscamos comprender el debate entre ciencia y política generado a través de la investigación con cloroquina (Clorocovid-19), desarrollada en Manaus, Amazonas. A través de una etnografía entretejida en documentos como videos, notas, cartas y mensajes transmitidos en las redes sociales, realizamos la descripción y análisis: (a) lo que llamamos activismo de la cloroquina en Manaus y su ofensiva; (b) la consiguiente reacción académica a los ataques. Ambos polos, a favor y en contra, hicieron uso de la construcción de una verdad, en la que la ciencia y la política son constantemente vinculadas.

PALABRAS CLAVE: Covid-19; Ciencias; Política; Cibercultura.

ABSTRACT: The current sanitary and pandemic crisis generated a set of global tensions, schemes and conflicts in different scientific, politic-party and economic spaces. The drugs hydroxychloroquine and chloroquine gained fame and expectations. What until then served only to treat malaria, now had a "cure possibility" for Covid-19. In this article we sought to understand the debate between science and politics that was generated through a research with chloroquine (Chlorocovid-19) and developed in Manaus, Amazonas. Through an ethnography woven with documents such as videos, notes, letters and messages broadcast on social media, we described and analyzed: (a) what we call chloroquine activity in Manaus and its offensive; (b) the consequent academic reaction to the attacks. Both poles - pro and contra - made efforts in the construction of a truth, in which science and politics cross-link.

KEYWORDS: Covid-19; Science; Politics; Cyberculture. 


\section{Introdução}

A lógica defendida pela ciência moderna é sedutora e, na prática, aparentemente inquestionável. Mas, é desse sistema que algumas tramas se utilizam de velhos personagens, em novos cenários e enredam grandes disputas. É assim que a ciência e a política têm se personificado em meio à pandemia de Covid-19, nos últimos meses. Questões de diversas ordens têm se emaranhado à tão esperada "cura" do adoecimento, elemento-chave dessa etnografia, que, de forma geral, nos fez compreender como a arena política, mediante disputas de versões, tem se imbricado ao debate do uso (ou não) da cloroquina no tratamento da Covid-19.

Por política não nos referimos apenas ao que aparece no Poder Executivo, no Congresso Nacional, às ações de corrupção ou outros dissabores que são transmitidos pelos meios de comunicação. Partimos do solo conceitual que política se refere também às interações entre os sujeitos, fazendo alusão às relações contínuas de poder e de forças que são exercidas a todo momento nas práticas sociais da vida cotidiana (Hur, 2013)

Nesse sentido, o artigo se articula com a preocupação da psicologia social no Brasil em reafirmar, mesmo que mais de três décadas depois da emergência da "crise da psicologia social”, abordagens psicossociológicas que se contrapõem às análises individualizantes das condições sociais e políticas que, ao invés de contribuírem para a expansão da democracia, reforçam a reprodução de desigualdades (Costa, 2020).

O debate calcado na relação entre psicologia social e política implica a reflexão e crítica sobre a própria concepção de ciência, como uma tentativa prática de tornar visível modos distintos de articular conhecimento (Costa \& Prado, 2016). Por isso, o foco deste artigo recai nas esferas da ciência, da política e do cotidiano.

Há duas principais entradas etnográficas que descrevemos e analisamos. A primeira, remete-se ao debate acusatório provocado pela divulgação dos resultados de uma pesquisa com cloroquina (CloroCovid-19), realizada em Manaus, que não coadunou com a tese defendida pelo atual presidente da república. E a segunda, as defesas institucionais e sistemáticas realizadas em prol dos/as pesquisadores/as após serem acusados de "assassinos" e "esquerdistas" nas redes sociais, sites de notícias e aplicativos móveis. Com isso, lançamos mão de abordagens e teorias sociais para darem a tônica das análises sobre as narrativas de "acusação" e "defesa", na busca pela construção de uma verdadel.

\section{Toda ciência tem um pouco de política ou toda política tem um pouco de ciência?}

Ao delimitar as fronteiras entre ciência e política, precisamos entender, inicialmente, os paradoxos dessa relação. Se, por um lado, por exemplo, a ciência é visibilizada e supostamente autorizada nos processos de organização e elaboração de políticas públicas, por outro, a aproximação cotidiana entre ciência e política pode ser uma das grandes ameaças a esse tipo de legitimidade. O contrário também é uma verdade. Quando as autoridades políticas utilizam-se dos preceitos científicos para "validar" suas formas de pensar, o aceite de um caráter puramente técnico na tomada de decisão parece se tornar quase que dispensável nesses processos (Mitre, 2016).

Trata-se de uma atividade política, na qual os/as cientistas se esforçam para definir e delimitar seu trabalho, distinguindo-se de outras atividades classificadas como não científicas e, por conseguinte, com o objetivo de gerar algum tipo de autonomia profissional. 
Contudo, também há uma necessidade de relativizar esse processo demarcado pela permeabilidade das fronteiras, tomando como ementa o movimento circular que se forma entre os elementos sociais, científicos, culturais e tecnológicos na construção do conhecimento (Mitre, 2016).

Ao problematizar as concepções de ciência e cotidiano, estamos sujeitos às condições históricas do momento em que se incorrem os fatos, de modo que a crítica de um tempo pode converter-se em um objeto criticado, possibilitando outras leituras da realidade em relação àquilo que já se constituiu (Costa \& Prado, 2016).

Crochík, Massola e Svartman (2016) falam de duas perspectivas para se pensar as pluralidades das condições políticas no campo da ciência. A primeira delas é decretar uma neutralidade política e ideológica da ciência e, por sua vez, conformar uma espécie de afastamento do compromisso com as transformações sociais. Direcionando, apenas, o precípuo da ciência como uma proposta de avanço neutro em sua corrida tecnológica.

A outra perspectiva traz a necessidade da atuação política dentro da ciência, já que as contribuições no escopo de transformações sociais são essenciais para as relações de vida. Podemos dizer, então, que quanto mais a ciência avança no fornecimento de condições e melhorias de saúde, trazendo estratégias mais confortáveis para a maioria das pessoas, mais se fortalecem as relações de produção que sustentam essas condições. Não obstante, as relações sociais continuam injustas. No atual contexto, por exemplo, quem teria acesso à cloroquina ou à hidroxicloroquina? Como os países em desenvolvimento responderiam ao tratamento com o uso desse fármaco - se autorizado - tomando como base os países desenvolvidos?

Nessa esteira, a economia política da produção e difusão do conhecimento biomédico na saúde pública pode também ter uma necessidade de se relacionar às estratégias de uma vida medicalizada, ou seja, transformar questões comuns da vida em um discurso e categorias biomédicas (Zorzanelli, Ortega, \& Bezerra, 2014). Com isso, a indústria farmacêutica pode defender interesses políticos, se afastar de propostas sociais mais justas, e pôr em xeque a própria ciência. Nessa direção, Lemos, Galindo, Rodrigues e Ferreira (2019) consideram que a indústria farmacêutica e o empresariado da saúde e da educação realizam contrapoderes, visando a silenciar e impedir uma crítica à medicalização das relações sociais. A medicalização é um processo no qual determinado comportamento e/ou problema não médico passa a ser definido como uma doença, transtorno ou problema, sendo direcionada à profissão médica a autorização para ofertar aos sujeitos algum tipo de tratamento (Conrad, 2007).

Na luta pela qualificação da democracia brasileira, um dos fundamentos da saúde pública é a própria política, aqui representada pela política de saúde, ou seja, as definições de incorporação de substâncias medicamentosas e protocolos pelos poderes sanitários expressam a relação entre ciência/evidências científicas e a capacidade de tomar decisões sanitárias. São relações muito imbricadas e dependentes, que vão além das estratégias de medicalização das relações sociais. A psicologia social, por sua vez, também nos faz retomar a dimensão cultural e política da própria saúde como um bem público na/da sociedade, e por meio de seus posicionamentos, tem se aproximado de debates nas associações de poder, nos movimentos sociais e nas entidades profissionais (Costa, 2020).

Adorno (2013) acredita que o conhecimento - ou a ciência propriamente dita é por si mesmo um dispositivo ${ }^{2}$ político. E é justamente por isso que o "público leigo" tem sido cada vez mais inserido no processo de construção científica. A ideia é fomentar uma representação social, cada vez mais equânime na construção do conhecimento. 
Todavia, as forjas ideológicas podem interferir diretamente naquilo que a ciência tem levado anos para legitimar. Isso nos mostra que a ciência faz parte de um campo social e, dessa forma, pode borrar as táticas de transformar os territórios modernos. A epistemologia é aqui defendida por meio de uma abordagem inclusiva, na qual diferentes atores/ atrizes externos/as ao sistema de conhecimento científico são convidados/as a contribuir, fortalecendo a relevância e a legitimidade de saberes e práticas. Assim, a demarcação de fronteiras entre a ciência e a política é frequentemente o resultado de uma complexa mistura de práticas sociais.

\section{Considerações sobre o trabalho de campo e suas dinâmicas}

A pesquisa CloroCovid-19, com sede em Manaus - contexto de todo o campo deste estudo - está sendo desenvolvida por um conjunto de mais de 70 pesquisadores/as vinculados em instituições de tradição, não somente na Região Norte, mas no Brasil. Dentre elas, a Fundação Oswaldo Cruz, a Fundação de Medicina Tropical Dr. Heitor Vieira Dourado, a Universidade do Estado do Amazonas e a Universidade de São Paulo.

Essas instituições acima relacionadas realizaram juntas um estudo clínico de fase II, duplo-cego, que contempla a aplicação de diferentes dosagens de cloroquina e hidroxicloroquina em indivíduos diagnosticados com Covid-19. Entre seus objetivos, está a avaliação da possibilidade dessas substâncias apresentarem ação benéfica no tratamento da Covid-19. Os resultados, mesmo que ainda parciais, foram divulgados como forma de compartilhar e reverberar informações sobre os achados da pesquisa, e garantir maior transparência e visibilidade no cenário de crise sanitária global. Em linhas gerais, a publicação dos resultados teve a função de alertar o mundo sobre a toxicidade de uma dose alta de cloroquina que, apesar de teoricamente parecer mais eficaz, estava causando mais danos do que benefícios no enfretamento à pandemia da Covid-19 (Borba et al., 2020).

A divulgação desses achados foi um grande marco na comunidade científica mundial, bem como no meio político. E para entender os posicionamentos dessas arenas, tivemos contato com sites de notícias que falavam sobre a pesquisa citada, artigos sobre os seus resultados, o parecer da Comissão Nacional de Ética em Pesquisa, notas de repúdio, notas de esclarecimento e vídeos que circularam por meio de redes sociais (Facebook ${ }^{\circledR}$, Twitter $®$ e Instragram $($ ) e grupos de Whats $A p p \AA$, que facilitaram o acesso aos documentos que se tornaram públicos, nos ajudando a compreender ambas as versões.

Esses materiais são fontes que interessam diretamente à problematização do estudo, e especialmente, à construção de subjetividades relacionadas com o tempo, o espaço, a cultura e a sociedade em si. Sua seleção seguiu rastros, redes e relações construídas em ciberespaços vinculados às universidades públicas do estado do Amazonas - sites e plataformas oficiais, bem como redes sociais e grupos de aplicativos para troca de mensagens. Com isso, foi possível elaborar uma descrição detalhada dos documentos (nome, data, autorias, meio de divulgação, conteúdo, acontecimentos locais e nacional), que nos ajudou a pensar as narrativas em torno da principal palavra-chave - "cloroquina" -, especialmente quando aparecia vinculada à pesquisa CloroCovid-19. A observação no campo ocorreu entre os meses de abril e junho de 2020.

Dessa forma, o trabalho etnográfico se situa no campo da cibercultura (Segata \& Rifiotis, 2016) e assume um lugar não neutro, em que seus artesãos estão implicados diretamente com a temática. As informações desse material advêm também da nossa 
atuação como professores-psicólogos-pesquisadores de universidades públicas do Estado do Amazonas, na linha de frente de intervenções em saúde mental no contex to da Covid-19. Trata-se, deste modo, de uma etnografia por afetação (Favret-Saada, 2005), forjada no âmbito da universidade pública, lócus de construção do conhecimento.

Partindo da premissa de que o/a pesquisador/a sempre parte de uma perspectiva ao iniciar seu estudo, a ideia de ser afetado no trabalho de campo, amplamente debatida por Favret-Saada (2005), é um fato que não pode ser ignorado. De acordo com Flores (2015), é necessário refletirmos sobre ser afetado, para que possamos continuar a produzir conhecimento. Se considerarmos que ser afetado pode impactar num processo de transformação do/a pesquisador/a, podemos, assim, compreender a capacidade de se desenvolver, de imaginar e experimentar sua cultura por meio do outro. Nessa direção, lançamos mão das reflexões de Hur e Lacerda (2017, p. 4): "não há neutralidade nas práticas psicológicas e tampouco nas científicas: há uma microfísica das relações de poder em todos os espaços e práticas sociais.” A psicologia social crítica rompe com as cristalizações instituídas e naturalizadas, na medida em que também se ocupa desse tipo de estudo.

\section{Resultados e Discussão}

Nos últimos anos, a mitigação de políticas de proteção social e bem-estar de governos de centro-esquerda no Brasil e no mundo abriu espaço para a expansão do neoliberalismo, conservadorismo, fundamentalismo religioso e outras dinâmicas grupais de extrema direita.

Desde o golpe da presidenta Dilma Rousseff, em 2016, o país enfrenta um clima de polarização e clivagem social, desdobrando-se em disputas, tramas e enredos bastante presentes no nosso cotidiano. Entretanto foi com as eleições de 2018 que as narrativas de antipetismo versus antibolsonarismo, direita versus esquerda, produzidas em nome da "anticorrupção", "valores cristãos" e da "família", acirrou ainda mais a polarização do povo brasileiro. Enlaçadas por meio de fakenewws, as disputas não se encerraram nas eleições, tornando-se tão vigente nos dias atuais. O Brasil já soltava pólvora em meio a tantos apagamentos sociais e históricos, mas os recentes conflitos políticos se tornaram a fagulha que faltava para explodir. E, para ilustrar este ponto, reconstruímos o debate público, político e acadêmico sobre o uso de fármacos para o tratamento da Covid-19.

Em 19 de março de 2020, com palavras de ordem, Donald Trump, presidente dos Estados Unidos da América (EUA), apontou a necessidade de rapidez na liberação de medicamentos com potencial ação para tratar a Covid-19. Dentre os fármacos citados, estavam a hidroxicloroquina e a cloroquina. Na ocasião, o presidente dos EUA fez referência positiva aos resultados ainda preliminares de seu uso. Um dia depois do pronunciamento de Trump, sites ${ }^{3}$ de notícias começaram a divulgar manchetes afirmando que após seu comentário, os remédios à base dos fármacos citados encontravam-se em falta nas farmácias brasileiras. De acordo com os noticiários, isso se deu após a convocação para que a entidade reguladora de medicamentos dos EUA, FoodandDrugAdministration, acelerasse a liberação das substâncias hidroxicloroquina e cloroquina.

Na mesma direção, em 26 de março de 2020, o presidente do Brasil assumiu um tom prescritivo dessas substâncias em rede nacional. Em várias de suas aparições, defendeu o uso da cloroquina, afirmou que não havia efeitos colaterais e ressaltou que os medicamentos já eram liberados no Brasil. Seria, então, um remédio milagroso descoberto pelo "Messias"? 
Os medicamentos hidroxicloroquina e cloroquina ganharam fama e expectativas. O que até então servia para o tratamento da malária, agora era a "possibilidade de cura" da Covid-19. A malária é uma das doenças mais incidentes no mundo, e no Brasil, a maioria dos casos se concentra na região amazônica. O diagnóstico recente e o tratamento adequado são partes fundamentais do programa de controle disponibilizado pelo Ministério da Saúde.

Conforme podemos observar no próprio manuscrito da pesquisa (Borba et al., 2020), a primeira conclusão foi que pacientes graves com Covid-19 não deveriam mais usar a dose recomendada no consenso chinês (uso do fosfato de cloroquina na dose de $500 \mathrm{mg}$ duas vezes por dia durante 10 dias) (Borba et al., 2020), fato que até a finalização das nossas observações não tinha evidências. Os resultados ainda apontaram que doses altas parecem ser seguras em pacientes com câncer, mas não em pacientes graves com Covid-19, em especial as pessoas idosas. O estudo não permitiu concluir se a cloroquina em doses baixas funciona para Covid-19, já que não trabalharam com grupo comparador de controle, is to é, sem usar a medicação.

Com esses resultados, instalou-se um cenário de jogos de verdades e disputas de narrativas. De um lado, os que "defendem a vida", e de outro, os "esquerdistas". Inaugurou-se um novo tempo, o ativismo pela cloroquina. O que significa dizer que as verdades aqui atribuídas são efeitos produzidos por mecanismos estratégicos de poder que insistem em imputar normas e classificações (Birman, 2002). A seguir, iremos contextualizar em duas seções: (a) a descrição do que chamamos de ativismo da cloroquina em Manaus e sua ofensiva; (b) a consequente reação acadêmica frente aos ataques.

\section{Ativismo da cloroquina em Manaus: a ofensiva por meio de notícias, imagens e vídeos que circulam}

"A rede é uma imagem adequada para descrever a maneira pela qual se pode ligar ou enumerar entidades díspares sem fazer suposições sobre níveis ou hierarquias” (Strathern, 2014, p. 304). É partindo dessa máxima que empreendemos nossos esforços para apresentar as cenas que analisamos - um conjunto de situações sociais e políticas - que ocorreram durante os meses de abril e maio no campo do ciberespaço (Segata\&Rifiottis, 2016).

Após quatro dias da publicação dos resultados da pesquisa em questão, que é o contexto do nosso campo, novas dinâmicas de comunicação política foram sendo estabelecidas. Em 15 de abril de 2020, a mobilização coletiva de testemunhos ganhou força para contestar os seus resultados. Uma manchete em um site nominado "Conexão Política" parecia esbravejar as conclusões dos/as pesquisadores/as, além de uma tentativa de produzir culpados:"Aplicando alta dosagem de cloroquina, 'estudo' usa pacientes de Covid-19 como cobaias para tentar desqualificar a hidroxicloroquina".

Outros aspectos como as frases: "experimento extremamente imprudente", "tamanha irresponsabilidade" e o uso de aspas quando se referia à metodologia do estudo "ensaio clínico”, foram utilizadas para culpar os/as responsáveis pela pesquisa. As acusações estavam em todo o corpo do texto: "os pesquisadores usaram alta dosagem de cloroquina (CQ), na tentativa de demonstrar que a hidroxicloroquina (HCQ) não é um medicamento seguro”.

Houve também um movimento na escrita da notícia de prescrever o uso da cloroquina, acionando a noção "coronavírus chinês", que é altamente difundido pelos apoiadores do presidente. Colocando de um lado a "alta dosagem", termo utilizado para se referir 
à quantidade utilizada pelos pesquisadores/as (cabe destacar o uso das aspas quando a autora do texto da notícia se referiu ao termo pesquisadores) e a "dosagem correta", categoria que emergiu na notícia para se referir à prescrição da autora que escrevia o texto. Posteriormente, outro movimento foi o de "Explicação do método utilizado", que, segundo a notícia, foi baseado na publicação do MedRxiv®. Fecha-se a matéria com ofensivas utilizando os termos "imprudência e irresponsabilidade", trazendo o teor político:

A mídia globalista e políticos de esquerda em vários países estão fazendo campanha contra o uso da hidroxicloroquina (HCQ), mesmo que o medicamento já tenha mostrado eficácia por milhares de médicos em diversos países. Esse "estudo" imprudente em Manaus não tem como ser defendido, pois atualmente há muita informação disponível. Ele parece ter sido tendencioso e irresponsável, colocando em risco a vida dos pacientes. As autoridades competentes brasileiras precisam urgentemente investigar a participação de cada indivíduo e órgão envolvido no estudo. É necessário averiguar se estes tinham ciência ou não do método de estudo utilizado, e se os próprios pacientes realmente foram informados sobre os riscos das altas dosagens aplicadas. (Conexão Politíca, 2020, p. 2)

A ofensiva contra os/as pesquisadores/as não ocorreu apenas em Manaus. Encontra-se articulada com outros estados brasileiros. A propagação de mensagens contra os/as pesquisadores/as e os resultados de seus estudos nas mídias digitais nacionais são também efeitos da polarização política existente no Brasil, que se tornaram ainda mais atinentes com os posicionamentos do presidente da república - "é só uma gripezinha" (The Lancet, 2020).

Em 16 de abril de 2020, a propagação de mensagens de textos e vídeos em aplicativos de mensagens e redes sociais, como o Facebook®, continua mobilizada. Com tom de "alerta” à sociedade, circula uma mensagem "denunciando" o caso dos/as pesquisadores/ as de Manaus que "estão matando vidas". Acompanhada de um link para acesso em um site de notícias (Figura 1), o alerta apresentou afirmações de que era um ato gerado pela "esquerda". O conteúdo do material que circulou fez emergir uma análise nossa, de que o objetivo era alertar a sociedade que pesquisadores/as tinham uma posição política eram de esquerda - e isso seria um "motivo" para que o estudo não tivesse credibilidade. Frente a nossa análise, o texto forjou-se mediante a teoria de que se produziu uma estratégia para fraudar os resultados obtidos pelo governo federal e, nesse sentido, eles estavam matando através de "overdose" em 81 pacientes com Covid-19, chamados de "cobaias": 


\section{Figura 1-Compartilhamento de notícia}

Encaminhada

URGENTE: Pesquisadores aplicam

'overdose' em 81 pacientes

'cobaias' com Covid-19 em Manaus

- http://www.alertamanaus.com

/urgente-pesquisadores-aplicam

-overdose-em-81-pacientes-cobaias

-com-covid-19-em-manaus/

ESTÃO MATANDO

A esquerda desesperada e apavorada com os resultados obtidos pelo Governo Federal.

$\checkmark b$ Sobre a alta dose aplicada em pacientes no Delphina

Fonte: Acervo da Pesquisa, 2020. Print dos autores.

No dia 17 de abril de 2020, o investimento de associar os/as pesquisadores/as com a ideia de esquerdistas ganha mais força e imagem. O mesmo site "Conexão Política" divulgou mais uma ofensiva por meio da notícia que continha a seguinte manchete: "A militância médica esquerdista por trás da pesquisa com alta dosagem de cloroquina em Manaus". Além do texto publicado, havia imagens dos/as pesquisadores/as, dados das redes sociais e publicações de cunho político-partidário da equipe de pesquisa. Cabe destacar que fomos averiguar a veracidade das imagens e não foi encontrado no perfil dos pesquisadores as imagens difundidas.

O texto-reportagem ${ }^{5}$ foi produzido com a proposta de deslegitimação da produção da pesquisa. As aspas, por exemplo, se faziam presentes mais uma vez, como podemos observar:

Um "estudo clínico" imprudente foi realizado em Manaus/AM com altas doses de cloroquina em pacientes do coronavírus chinês ( $S A R S-C o V-2)$, na tentativa de desqualificar o uso da hidroxicloroquina (HCQ) e demonstrar que ela não é um medicamento seguro.

O texto-reportagem segue a trama de um dossiê de publicações nas redes sociais de toda a equipe de pesquisa e estrategicamente aglutinaram informações que faziam referência aos seguintes aspectos: fotos do perfil em redes sociais com filtros que declaravam apoio à candidatura para presidenciáveis, em 2018, no caso, Fernando Haddad; imagens do vínculo empregatício dos/as servidores/as da Fundação Oswaldo Cruz, instituição que foi fortemente atacada pelo presidente; imagens da identidade funcional vinculada à Organização Mundial de Saúde (OMS), subordinada à Organização das Nações Unidas (ONU), postada por membro da equipe de pesquisa; postagens relacionadas ao questionamento do assassinato da vereadora Marielle Franco, no Rio de Janeiro; fotos de perfis com filtros de campanha à visibilidade Lésbica, Gay, Bissexual, Travesti e Transexual (LGBT); postagens relacionadas aos sindicatos; à campanha Lula Livre; e à defesa da resistência da Universidade do Estado do Rio de Janeiro (UERJ), quando vivenciou a crise econômica em 2015. 
Lançando mão das reflexões de Latour (2008), essa característica de comunicação humana, mediada e vivenciada por nós no campo, não apenas transportou efeitos, sem transformá-los, mas deu origem a uma nova tradução que foi identificar a ironia, no caso das aspas e a deslegitimação do estudo e da equipe de pesquisa na busca de produzir uma narrativa que desqualificasse a pesquisa, em detrimento da posição política da equipe responsável. Nesse sentido, entre as fronteiras da ciência e da política, torna-se clara a observação de jogos de verdade como efeito de jogos de poder, relativos a certos interesses que determinam algumas premissas como verdadeiras, e outras, como falsas (Birman, 2002).

Somado às diversas estratégias da ofensiva contra os pesquisadores, um vídeo começou a circular no início de mês de maio de 2020. De modo inusitado, com palavras de ordem, o vídeo ${ }^{6}$ com duração de 21 minutos e 51 segundos, iniciava com a seguinte mensagem: "Esse vídeo salva vidas!! Compartilhe! Espalhe!" Logo depois, veio uma frase de efeito "Assassinato de Reputação MATA. Investigação e Autópsia."

“Não vamos politizar a questão, ok?” Essa é uma das frases disparadoras desse material. A produção do vídeo faz um esforço para expor detalhes metodológicos da pesquisa CloroCovid-19, comparando-a com outras desenvolvidas na China, Costa Rica e França, por exemplo. O material debruça-se em fotos da equipe de pesquisa, questiona a instituição à qual estão vinculados e faz conclusões prescritivas da medicação. Ao fim, conclui que a pesquisa em questão "não é ciência”.

É perceptível o quanto a organização do material se direciona para uma condução quase que "alfabetizadora" sobre o uso da cloroquina. Passados dez minutos de exposição, a narradora de fotos, recortes de outros vídeos e montagens de redes sociais, declara: "eu não sou médica, e nem farmacêutica, mas sei ler um artigo com estatística”. Numa tentativa de se aproximar ou nivelar-se a qualquer ouvinte "leigo", ela afirma que houve uma superdosagem do uso da cloroquina no estudo desenvolvido em Manaus, e que a substância também foi associada à hidroxicloroquina, diferentemente de outros estudos similares, que não fizeram essa associação.

Ao longo do vídeo, há uma excessiva tentativa de repetir a palavra cloroquina, que quando transcrita para esse processo de etnografar, apareceu mais de trezentas vezes seja a cloroquina, a hidroxicloroquina ou o difosfato de cloroquina.

Para além de um debate biomédico, no qual é presumível possíveis vieses no processo de pesquisa (seleção, informação e tantos outros), a narradora sempre retomava a ideia de que qualquer desvio na coleta, análise, interpretação, publicação ou revisão de dados, tinha o objetivo de assassinar ou matar as pessoas. Em um contexto plasmado pelo medo, ansiedade e insegurança, já vivenciados pela pandemia, essas conclusões podem ainda potencializar efeitos subjetivos diversos em pessoas, grupos ou comunidades inteiras.

Face a esses aspectos, no Brasil, a psicologia e sua prática são historicamente políticas. E por isso se constitui de posicionamentos que visam à produção de uma sociedade mais igualitária, justa e democrática e, por conseguinte, com menor sofrimento psicossocial. Essas práticas podem ser observadas por meio das entidades que assumem, em seus saberes e dispositivos técnicos de intervenção, posicionamentos históricos-sociais que exercem relações na gestão da vida, tanto individual como social (Hur \& Lacerda, 2017).

Tomando como base esses dispositivos técnicos, a narração do vídeo trouxe ainda o Parecer n. 04/2020 do Conselho Federal de Medicina (2020), que autoriza o uso dessas substâncias, mediante critério médico e consentimento do paciente. Instalou-se, portanto, um novo jogo de poder, agora em outros espaços. Por fim, as imagens e as falas, 
quase que em um só tom, concluíam que a principal questão do estudo era o comunismo; ou seja, diferente daquilo que se tinha prometido ou questionado no início do vídeo, a narradora politizou a questão. Tal fato nos leva a destacar a pluralidade das condições políticas no campo da ciência.

\section{Em resposta à ofensiva através das notas que circulam: o "repúdio" e o "esclarecimento"}

No dia 11 de abril de 2020, foram publicados no portal científico MedRxiv® os resultados preliminares da pesquisa CloroCovid-19 (Borba et al., 2020). Logo em seguida, inúmeras instituições públicas, que atuam no campo da pesquisa, começaram a emitir notas de esclarecimentos em respostas aos ataques que a equipe de pesquisadores/as vinha sofrendo, especialmente àqueles/as de Manaus.

Nesse mesmo dia, o Estado do Amazonas decretou o status de calamidade pública, e ampliou fortemente as medidas de restrição de circulação de pessoas. A tensão gerada pelos resultados da pesquisa, a política de austeridade implantada, e tantos outros elementos midiáticos locais e nacionais trouxeram à tona uma avalanche de documentos oficiais nas páginas das universidades, centros de estudo e órgãos da ciência em apoio aos/ às pesquisadores/as envolvidas no trabalho de pesquisa, com destaque para o coordenador Marcus Vinícius Guimarães de Lacerda, pesquisador do Instituto Leônidas \& Maria Deane (Fiocruz-Amazonas) e do Programa de Pós-graduação em Medicina Tropical, da Universidade do Estado do Amazonas (UEA) e Fundação de Medicina Tropical Heitor Vieira Dourado (FMT-HVD).

O primeiro e mais replicado documento foi intitulado "Direito de resposta e esclarecimentos", e assinado pelo pesquisador principal em nome da equipe de trabalho. Buscou-se explicar que a escolha de uma dose alta, o principal alvo de ataque e ofensas, teve o seguinte raciocínio científico: (a) doses elevadas têm maior atividade antiviral in vitro, isto é, em laboratório, sendo mais altas do que a dose usada para malária, por exemplo; (b) é a mesma dose utilizada na China, por peso das participantes, e que está contida atualmente no consenso chinês de tratamento de Covid-19; (c) utilizou-se em pacientes com baixa perfusão intestinal, e que, portanto, absorvem menos a medicação; (d) em uma doença que se revelou, principalmente no mundo ocidental, muito letal, o risco de benefício da eficácia versus de efeitos colaterais, de diferentes doses, precisava ser avaliado e conhecido dentro de parâmetros científicos; (e) existe boa segurança dessa mesma dose alta em pacientes com câncer, em vários estudos publicados, que a utilizaram por períodos ainda mais longos, 28 dias; (f) a dose aplicada foi inicialmente utilizada pelo General Hospital de Massachussets, nos Estados Unidos.

Outro ponto também esclarecido nas notas é que assim que os/as pesquisadores/ as evidenciaram as onze mortes de pessoas idosas que participaram do estudo, que já é um perfil grave para a Covid-19, o comitê do estudo encerrou a fase exploratória, informou à Comissão Nacional de Ética em Pesquisa (CONEP), por meio da Plataforma Brasil, e divulgou os resultados preliminares em periódicos internacionais (Sociedade Brasileira de Virologia, 2020). 
Esses apontamentos de esclarecimentos trouxeram respostas em defesa de uma ciência neutra. As narrativas foram replicadas também pelas Sociedades Brasileira de Infectologia e de Imunologia que declarararam que os pesquisadores não pautam suas ações por vinculações ideológicas ou partidárias e seu compromisso é apenas com a boa ciência e pediu para deixarem os cientistas trabalharem em paz. A nota dizia que a ignorância e o obscurantismo só podem ser combatidos pela ciência, pela ética e pelo conhecimento. A defesa pautada pelo cientificismo era também enunciada em discursos de ataques.

A Universidade de Brasília ${ }^{7}(\mathrm{UnB})$ posicionou-se, e repudiou veementemente os ataques sofridos pelos/as pesquisadores/as, destacando o percurso acadêmico do pesquisador Marcus Lacerda na instituição. Médico, graduado e pós-graduado pela UnB, foi um dos criadores do Instituto Nacional de Ciência da Eliminação da Malária (Instituto Elimina), e vem desenvolvendo renomadas pesquisas sobre a malária há mais de 20 anos no país, com forte influência no contexto amazônico. Por fim, a nota ressaltou que a UnB reitera seu compromisso com a defesa da ciência, da ética e do respeito ao próximo.

Nesse mesmo sentido, mais de quinze instituições fizeram menção em apoio aos grupos de pesquisadores/as, como a Universidade de São Paulo (USP), a Universidade Estadual do Amazonas (UEA), a Universidade Federal do Amazonas (UFAM), a Fundação Oswaldo Cruz (Fiocruz), a Sociedade Brasileira para o Progresso da Ciência, a Sociedade Brasileira de Medicina Tropical (SBMT), a Sociedade Brasileira de Bioética (SBB), a Associação Brasileira de Saúde Coletiva (ABRASCO), o Centro Brasileiro de Estudos de Saúde (CEBES), a Rede Unida, a Academia Brasileira de Ciências, bem como vários Programas de Pós-Graduação em diferentes áreas e em distintas regiões do país.

Contudo, um documento nos chamou atenção. O Conselho Nacional de Saúde (CNS, 2020), por meio da Comissão Intersetorial de Ciência, Tecnologia e Assistência Farmacêutica (CICTAF), veio a público manifestar solidariedade aos/às pesquisadores/as do estudo, e reforçar que o desenho metodológico seguiu as diretrizes emanadas pela Resolução n. 466/2012 da CNS, e foi aprovada na CONEP sob registro CAAE: 30152620.1.0000.0005.

De forma geral, os documentos destacavam a importância da ciência e sua neutralidade (ou suposta neutralidade), trazendo o fenômeno da ideologia política como uma questão que não deve ser colocada em pauta pelo cientificismo, e de forma "apartidária”, constroem as ideias em uma narrativa democrática no Brasil, pautada nos pilares constitucionais. Seguindo essa esteira, se é possível identificar o jogo de verdade sobre o qual repousavam certezas e descrever os movimentos que produziram as mudanças em seu fundamento, estamos mais próximos de entender as relações entre os sujeitos (Birman, 2002).

Em entrevista ao Jornal Gazeta do Povo (Drechsel, 2020), Marcus Lacerda fala que o trabalho de pesquisa com uma substância que pode matar (em altas dosagens), em que a morte é um dos desfechos mais comuns da própria doença, faz com que a conotação desse cenário mórbido se expresse para além do que está posto nos resultados da pesquisa. Afirma, inclusive, que "quem lê o artigo sabe que não foi absolutamente nada disso ... e o problema desse assunto é que ele está muito politizado." Seria então a política uma variável da conformação da ciência?

E foi assim que uma cascata de notas de apoio à ciência, fazendo menção ao estudo CloroCovid-19, teceu uma rede de solidariedade em sites oficiais e mídias sociais. Os/as pesquisadores/as colocaram "a ciência em ação", como diria Latour (2008, p. 10), e esse movimento em massa se fez como uma verdadeira reivindicação histórica daquilo que a ciência tem trilhado há anos - um lugar "oficial” na sociedade. 


\section{Reticulando ciência e política: da acusação à defesa}

Nessa etnografia, composta de dois atos inter-relacionados - acusação e defesa (repúdio e esclarecimentos), configuram-se dois contextos, entre os quais, se estabelece uma disputa de sentidos e práticas em torno dos jogos de verdades no contexto da pandemia da Covid-19: o ativismo pró-cloroquina e hidroxicloroquina e as evidências científicas contra os fármacos.

O que essa breve etnografia sugere é que as ações pró e contra os medicamentos forjaram-se nos últimos meses, em uma regra que indica a existência ou não da cura da Covid-19, dividida em dois grupos de jogadores da verdade. De um lado, um grupo de ativistas políticos do Presidente Jair Bolsonaro (sem partido), que encontrou em suas declarações públicas um meio privilegiado para atacar ideologias políticas que divergem de sua posição e difamar instituições públicas de ensino e pesquisa, com vistas a sustentar o discurso de "aparelhamento ideológico" pela "esquerda". E de outro, pesquisadores/as com um perfil biomédico, acionando discursos de neutralidade e sem partido, com vistas a obter respeitabilidade social e científica, tentando afastar ciência de política.

Isso também pode ser visto como uma tática política, ao buscar delimitar fronteiras, isto é, a ciência, por meio de suas instituições e cientistas, ao sentirem-se ameaçados, se colocam no lugar de neutralidade. Então, mesmo que parte das instituições científicas e cientistas tenham dificuldades em vislumbrar o atravessamento político de suas práticas profissionais, em suas relações de forças e efeitos, sempre há produção de regimes de poder. Como lembra Birman (2002), o trabalho de compreender determinados jogos, pela própria leitura crítica e insistente da sua formação, cristalização e enraizamento, pode enunciar outros jogos de verdade.

\section{Considerações finais}

Ao observar os fatos por meio de documentos, redes sociais, aplicativos de mensagens e portais, mediante um trabalho sistemático, contínuo, capilar e vigilante, notamos que há um investimento de ativistas da cloroquina na desmoralização das instituições que produzem conhecimento. Há uma mobilização ancorada em um discurso de neutralidade e sem partido. Do outro lado, instituições e pesquisadores/as, acionaram estratégias que se tornaram repetidas e semelhantes à da oposição. Também foi comum observar o discurso de neutralidade e sem partido nos documentos para validar a verdade científica.

Com isso, a complexidade que, por vezes, permeia os conflitos e as relações dos atores/atrizes sociais e instituições envolvidos no caso em tela, é abandonada; e as questões que emergem nesse cenário são abordadas como algo estritamente cientificista. Em outras palavras, baseada na narrativa de neutralidade, articulada à racionalidade da política da cura ou da morte, marcadamente essencialista, maniqueísta e dicotômica, encerra o fenômeno entre acusação e defesa.

As possíveis propostas para desvelar as regras do jogo indicam que as lutas e os movimentos de resistência continuam ativos, e a psicologia social tem um papel fundamental na promoção de deslocamentos, tanto dentro como fora da área, seja nas práticas de pesquisadores/as ou de profissionais. Enquanto as relações de saber e poder continuam sendo acionadas por meio de vários equipamentos, como leis, protocolos e resoluções biomédicas, 
os jogos de aquecimento com outros agenciamentos políticos - inclusive instituídos pela psicologia social - precisam interferir na gestão dessas relações e na produção de novas subjetividades. Assim, o conhecimento científico não se torna um mero complexo de regulação, mas uma miragem de emancipação política.

\section{Notas}

1 O termo verdade quando aparece no texto, grafado em itálico, diz respeito às proposições ou afirmações conceituais ligadas à produção discursiva de determinado campo do saber. Podemos dizer que os enunciados de verdade - ou produções discursivas - fazem parte dos jogos que lhes instituem determinadas regras. De acordo com Birman (2002, p. 307) "enunciar a existência de uma regra é indicar a existência de algo que é da ordem da invenção e do arbitrário, que seria constitutivo de toda e qualquer regra. Se esta é arbitrária, no entanto, não quer dizer que seja marcada pela arbitrariedade no sentido negativo da palavra, pois seria sempre compartilhada pelos possíveis jogadores, naquilo que ao mesmo tempo autoriza e proíbe”.

2 Por dispositivo, entendemos um "conjunto decididamente heterogêneo que engloba discursos, instituições, organizações arquitetônicas, decisões regulamentares, leis, medidas administrativas, enunciados científicos, proposições filosóficas, morais, filantrópicas. Em suma, o dito e o não dito são os elementos do medispositivo. $\mathrm{O}$ dispositivo é a rede que se pode tecer entre estes elementos." (Foucault, 2008, p. 244)

3 Recuperado dehttps://conexaopolitica.com.br/ultimas/a-militancia-medicaesquerdista-por-tras-da-pesquisa-com-alta-dosagem-de-cloroquina-em-manaus /

4. Recuperado dehttps://conexaopolitica.com.br/ultimas/a-militancia-medicaesquerdista-por-tras-da-pesquisa-com-alta-dosagem-de-cloroquina-em-manaus $/$,

5 Recuperado de https://conexaopolitica.com.br/ultimas/a-militancia-medicaesquerdista-por-tras-da-pesquisa-com-alta-dosagem-de-cloroquina-em-manaus /

6 Recuperado de https://www.youtube.com/watch?v=eSBNhqfiDvA

7 Recuperado de https://noticias.unb.br/76-institucional/4078-nota-de-repudioa-ataques-sofridos-por-pesquisadores-que-estudam-a-eficacia-da-cloroquina 


\section{Referências}

Adorno, T. W. (2013). Introducción a la dialéctica (M. Dimópulos, trad.). Buenos Aires: Eterna Cadencia.

Birman, J. (2002). Jogando com a verdade. Uma leitura de Foucault. Physis: Revista de Saúde Coletiva, 12(2),301-324. Recuperado de https://doi.org/10.1590/So103-73312002000200007

Borba, M. G. S., Val, F. A., Sampaio, V. S., Alexandre, M. A. A., Melo, G. C., Brito, M. et al.(2020). Chloroquinediphosphate in two different dosages as adjunctive therapy of hospitalized patients with severe respiratory syndrome in the context of coronavirus (SARS-CoV-2) infection: Preliminary safety results of a randomized, double-blinded, phase IIb clinical trial (CloroCovid-19 Study). MedRxiv, 1, 1-30. Recuperado de https://doi.org/10.1101/2020.04.07.20056424

Conrad, P. (2007). Themedicalization of society: Onthetransformation of human conditionsintotreatabledisorders. Baltimore, MA: The John Hopkins University Press.

Conselho Federal de Medicina. (2020). Processo-consulta CFM n. 8/2020 - Parecer CFM n.4/2020. Brasília, DF: Autor. Recuperado de https://sistemas.cfm.org.br/normas/visuali$\mathrm{zar} /$ pareceres/BR/2020/4

Conselho Nacional de Saúde. (2020). \#FrentePelaVida: Nota de solidariedade e pela vida. Brasília: Autor. Recuperado de http://conselho.saude.gov.br/ultimas-noticias-cns/1161-frentepelavida-nota-de-solidariedade-e-pela-vida

Costa, F. A. (2020). A produção da psicologia social sobre temas políticos a partir de aspectos históricos. Psicologia Ẽ Sociedade, 32, e 187198. Recuperado de https://doi.org/10.1590/1807$\underline{-0310 / 2020 v 32187198}$

Costa, F. A. \& Prado, M. A. M. (2016). Crítica, política e psicologia social: A mudança social e o lugar da ação intelectual na luta política. Estudos de Psicologia (Natal), 21(2),2 16-227. Recuperado de https://doi.org/10.5935/1678-4669.20160021

Crochík, J. L., Massola, G. M., \& Svartman, B. P. (2016). Ciência e Política. Psicologia USP, 27(1), 1-5. Recuperado de https://doi.org/10.1590/0103-656420162701

Drechsel, D. (2020, 16 de abril). Entrevista: Após 11 mortes, médico explica pesquisa com cloroquina e critica uso político do estudo. Gazeta do Povo. Recuperado de https://www.gazetadopovo.com.br/vida-e-cidadania/apos-11-mortes-medico-explica-pesquisa-com-cloroquina-e-critica-uso-politico-do-estudo

Favret-Saada, J. (2005). "Ser afetado". Cadernos de campo, 13(13), 155-161.

Flores, L. V. (2015). O sentimento do antropólogo. Ponto Urbe, 17(1), 1-9. Recuperado de https://journals.openedition.org/pontourbe/2923\#text. https://doi.org/10.4000/pontour$\underline{\text { be.2923 }}$

Foucault, M. (2008). Microfísica do poder (26a ed.). Rio de Janeiro: Graal.

Hur, D. U. (2013). Esquizoanálise e política: proposições para a Psicologia Crítica no Brasil. Teoría y Crítica de laPsicología, 3(2),264-280. Recuperado de http://www.teocripsi.com/ojs/ index.php/TCP/article/view/111

Hur, D. U. \& Lacerda, F. (2017). Psicologia e Democracia: da Ditadura Civil-Militar às Lutas pela Democratização do Presente. Psicologia: Ciência e Profissão, 37(n.spe),3-10. Recuperado de https://www.scielo.br/scielo.php? script $=$ sci isoref\&pid=S1414-98932017000500003\&lng= pt\&tlng=pt. doi: https://doi.org/10.1590/1982-3703190002017 
Latour, B. (2008). Disinventare la Modernità: conversazioni com François Ewald. Milão, ITA:Elèuthera.

Lemos, F., Galindo, D., Rodrigues, R., \& Ferreira, E. (2019). Resistências frente à medicalização da existência. Fractal: Revista de Psicologia, 31(2), 158-164. https://doi.org/10.22409/19840292/v31i2/5567

Mitre, M. (2016). As relações entre ciência e política, especialização e democracia: a trajetória de um debate em aberto. Estudos Avançados, 30(87), 279-298. https://doi.org/10.1590/So103$\underline{40142016.30870016}$

Segata, J.\&Rifiotis, T. (Eds.). (2016). Políticas Etnográficas no Campo da Cibercultura.Brasília, DF: ABA Publicações; Joinville: Editora Letradágua.

Sociedade Brasileira de Virologia. (2020). Nota sobre a necessidade de proteger a integridade e a vida dos pesquisadores brasileiros. Recuperado de https://sbv.org.br/sbv/nota-sobre-a-necessidade-de-proteger-a-integridade-e-a-vida-dos-pesquisadores-brasileiros/

Strathern, M. (2014). Cortando a rede. In O efeito etnográfico e outros ensaios (I. Dulley, trad., pp. 295-320). São Paulo: CosacNaify.

The Lancet. (2020). Covid-19 in Brazil: “So what?”.Lancet, 395(10235),1461.Recuperado de https://www.thelancet.com/pdfs/journals/lancet/PIISo 140-6736(20)31095-3.pdf. doi: https://doi.org/10.1016/So 140-6736(20)31095-3

Zorzanelli, R. T., Ortega, F., \& Bezerra, B. (2014). Um panorama sobre as variações em torno do conceito de medicalização entre 1950-2010. Ciência E̊ Saúde Coletiva, 19(6), 1859-1868. https://doi.org/10.1590/1413-81232014196.03612013

\section{ANDRÉ LUIZ MACHADO DAS NEVES https://orcid.org/0000-0001-7400-7596}

Psicólogo, doutor em Saúde Coletiva, na área de concentração em ciências humanas e saúde, pelo Instituto de Medicina Social (IMS) da Universidade do Estado do Rio de Janeiro (UERJ), mestre em Psicologia pela Universidade Federal do Amazonas (UFAM) e especialista em Psicologia Educacional com ênfase em psicopedagogia preventiva.

Endereço: Av. Carvalho Leal, n. 1777, Cachoeirinha, Manaus, AM.

E-mail: andre machadostm@hotmail.com

\section{BRENO DE OLIVEIRA FERREIRA}

\section{https://orcid.org/0000-0002-0979-3911}

Psicólogo, pedagogo, doutor em Saúde Coletiva pelo Instituto Fernandes Figueira da Fundação Oswaldo Cruz (IFF-Fiocruz), mestre em Ciências e Saúde pela Universidade Federal do Piauí (UFPI) e docente dos cursos de graduação e mestrado em Psicologia na Universidade Federal do Amazonas (UFAM).

E-mail: breno.oli@hotmail.com 


\begin{tabular}{|c|c|}
\hline Histórico & $\begin{array}{l}\text { Submissão: 01/07/2020 } \\
\text { Revisão: 24/07/2020 } \\
\text { Aceite: 27/07/2020 }\end{array}$ \\
\hline $\begin{array}{l}\text { Contribuição } \\
\text { dos autores }\end{array}$ & $\begin{array}{l}\text { Concepção: A.L.M.N.; B.O.F. } \\
\text { Coleta de dados: A.L.M.N.; B.O.F. } \\
\text { Análise de dados: A.L.M.N.; B.O.F. } \\
\text { Elaboração do manuscrito: A.L.M.N.; B.O.F. } \\
\text { Revisões críticas de conteúdo intelectual importante: } \\
\text { A.L.M.N.; B.O.F. } \\
\text { Aprovação final do manuscrito: A.L.M.N.; B.O.F. }\end{array}$ \\
\hline $\begin{array}{l}\text { Consentimento } \\
\text { de uso de imagem }\end{array}$ & Não se aplica. \\
\hline $\begin{array}{l}\text { Aprovação, ética } \\
\text { e consentimento }\end{array}$ & Não se aplica. \\
\hline Financiamento & Não houve financiamento. \\
\hline
\end{tabular}

